\title{
The Antibacterial Synthetic Flavonoid BrCl-Flav Exhibits Important Anti-Candida Activity by Damaging Cell Membrane Integrity
}

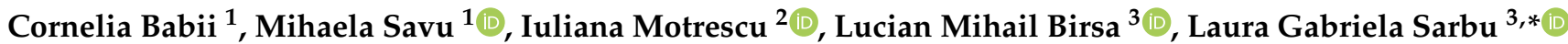 \\ and Marius Stefan $1, *$ (D) \\ 1 Biology Department, Faculty of Biology, The Alexandru Ioan Cuza University of Iasi, Bld. Carol I, Nr. 11, \\ 700506 Iasi, Romania; corneliababii@yahoo.ro (C.B.); mihaelasavu2@gmail.com (M.S.) \\ 2 Sciences Department, Research Institute for Agriculture and Environment, Iasi University of Life Sciences, \\ 3 Sadoveanu Alley, 700490 Iasi, Romania; imotrescu@yahoo.com \\ 3 Faculty of Chemistry, The Alexandru Ioan Cuza University of Iasi, Bld. Carol I, Nr. 11, 700506 Iasi, Romania; \\ lbirsa@uaic.ro \\ * Correspondence: laura.sarbu@uaic.ro (L.G.S.); stefanm@uaic.ro (M.S.)
}

Citation: Babii, C.; Savu, M.;

Motrescu, I.; Birsa, L.M.; Sarbu, L.G.; Stefan, M. The Antibacterial Synthetic Flavonoid BrCl-Flav Exhibits Important Anti-Candida Activity by Damaging Cell Membrane Integrity. Pharmaceuticals 2021, 14, 1130 . https://doi.org/10.3390/ph14111130

Academic Editor: Poce Giovanna

Received: 9 October 2021

Accepted: 3 November 2021

Published: 6 November 2021

Publisher's Note: MDPI stays neutral with regard to jurisdictional claims in published maps and institutional affiliations.

Copyright: (c) 2021 by the authors. Licensee MDPI, Basel, Switzerland. This article is an open access article distributed under the terms and conditions of the Creative Commons Attribution (CC BY) license (https:/ / creativecommons.org/licenses/by/ $4.0 /)$.

\begin{abstract}
Infections caused by Candida are very difficult to treat due to increasing antifungal resistance. Recent studies showed that patients with Candida infections resistant to fluconazole have very few treatment options. Therefore, finding new efficient antifungal agents is a matter of medical high priority. The aim of this study was to explore the antifungal potential of $\mathrm{BrCl}-\mathrm{flav}$-a representative of a new class of synthetic flavonoids with bromine as halogen substituent at the benzopyran core against four Candida clinical strains. Determination of minimum inhibitory concentration and minimum fungicidal concentration along with the time kill assay indicated a strong antifungal effect of $\mathrm{BrCl}-$ flav against C. albicans, C. parapsilosis, C. krusei and C. glabrata. The investigation of anti-Candida mechanism of action using fluorescence microscopy and scanning electron microscopy revealed that $\mathrm{Br}-\mathrm{Cl}$ flav could inhibit fungal growth by impairing the membrane integrity, the resulting structural damages leading to cell lysis. BrCl-flav also showed important anti-virulence properties against Candida spp., inhibiting biofilm formation and yeast to hyphal transition. A strong synergistic antifungal effect against C. albicans strain was observed when $\mathrm{BrCl}$-flav was used in combination with fluconazole. BrCl-flav has a good potential to develop new effective antifungal agents in the context of Candida spp. multidrug resistance phenomenon.
\end{abstract}

Keywords: anti-Candida; synthetic flavonoid; antifungal agents; mechanism of action; synergistic effect

\section{Introduction}

Candida pathogenic species are considered a major cause of morbidity and mortality worldwide, representing a serious threat to public health [1]. The most frequently isolated pathogenic species is C. albicans, causing infections which can cause $40-60 \%$ mortality, especially in immunocompromised patients [2]. Other species such as C. glabrata, C. tropicalis, C. parapsilosis and C. krusei have been also isolated and are considered the main causative agents in 50-70\% of systemic fungal infections [1,3].

Antifungal agents such as azoles, polyenes, echinocandins, nucleoside analogs and allylamines are used to control Candida infections. Among the available anticandidal agents, fluconazole (a type of azole) is one of the most frequently used drugs for the treatment of Candida infections [4]. However, antifungal chemotherapy is challenged by multidrug resistance, phenomenon extensively documented in the literature among Candida species, especially in relation to azoles [1]. One of the major factors behind the multiple drugs resistance is the ability of Candida spp. to form biofilms on different surfaces [5]. Due to their resistance to multiple drugs, biofilm cells survive to antifungals concentrations 1000-fold higher than those which inhibit planktonic cells [6]. Therapeutical limitations 
caused by multidrug resistance phenomenon make the control of Candida infections a major challenge for modern medicine. Therefore, the design of new drugs derived from the traditional ones and the identification of new antifungal molecules are fundamental to face the alarming increase of Candida infections rate [1].

Flavonoids, a group of natural heterocyclic compounds, are potentially good candidates for developing new antifungal agents. Traditionally, flavonoids have been used for centuries to treat human diseases due to their antimicrobial, anti-allergic, anti-inflammatory and antioxidant activities. The antifungal properties of natural flavonoids are well documented [7]. Nowadays, antifungal research is focused on semisynthetic and synthetic flavonoids due to their higher antimicrobial activity [7-10]. However, at this moment little is known about antifungal potential of synthetic flavonoids [8].

In this study, a representative of a new class of synthetic sulfur containing tricyclic flavonoids with bromine as halogen substituent at the benzopyran core (BrCl-flav) was tested in vitro for antifungal activity against four Candida clinical strains: C. albicans, C. parapsilosis, C. krusei and C. glabrata. We previously showed that BrCl-flav is an effective antibacterial agent, with stronger bacteriostatic and bactericidal effect at lower concentrations than those described in the earlier reports [11]. Based on its potent antibacterial properties, $\mathrm{BrCl}$-flav has a good potential in developing new effective antifungal agents in the context of Candida spp. multidrug resistance phenomenon. Nothing is known so far about the $\mathrm{BrCl}$-flav antifungal activity, therefore we focused on BrCl-flav mechanism of action and the effect in combination with fluconazole against $C$. albicans resistant clinical isolates. The novelty of the present work is related to the proposal of a synthetic flavonoid-BrCl-flav as a new antifungal agent with good potential to develop effective drugs in the context of Candida spp. multidrug resistance phenomenon.

\section{Results}

\subsection{Antifungal Activity of Synthetic Flavonoid}

BrCl-flav showed a promising inhibitory activity against all tested Candida isolates at concentrations as low as $15.62 \mu \mathrm{g} / \mathrm{mL}$ and fungicidal activity at a concentration of $31.25 \mu \mathrm{g} / \mathrm{mL}$ (Table 1).

Table 1. Minimum inhibitory concentration and minimum fungicidal concentration of BrCl-flav against tested Candida species.

\begin{tabular}{ccccc}
\hline \multirow{2}{*}{$\begin{array}{c}\text { Candida sp. } \\
\text { Strains }\end{array}$} & \multicolumn{2}{c}{ BrCl-Flav } & DMSO & Fluconazole \\
\cline { 2 - 5 } & MIC $(\mu \mathrm{g} / \mathbf{m L})$ & MFC $(\mu \mathrm{g} / \mathbf{m L})$ & MIC $(\mu \mathrm{g} / \mathbf{m L})$ & MIC $(\mu \mathrm{L} / \mathbf{m L})$ \\
\hline C. albicans & 15.62 & 31.25 & $>250$ & 1000 \\
C. parapsilosis & 15.62 & 31.25 & $>250$ & 3.9 \\
C. krusei & 15.62 & 31.25 & $>250$ & 62.5 \\
C. glabrata & 15.62 & 31.25 & $>250$ & 125 \\
Candida krusei & 15.62 & 31.25 & 125 & 62.5 \\
ATCC 6258 & & & & \\
\hline
\end{tabular}

$\overline{\mathrm{MIC}}=$ minimum inhibitory concentration; $\mathrm{MFC}=$ minimum fungicidal concentration; the values are mean for at least three replicates.

\subsubsection{BrCl-Flav Inhibited Candida spp. Growth in a Dose and Time Dependent Manner}

The MIC value $(15.62 \mu \mathrm{g} / \mathrm{mL})$ was used as reference to evaluate the effect of BrCl-flav on fungal growth. As the growth dynamics curves depicted in Figure 1 show, no significant inhibition was recorded when $\mathrm{BrCl}$-flav was used at a concentration of $7.81 \mu \mathrm{g} / \mathrm{mL}$ $(1 / 2 \mathrm{MIC})$. When used at a concentration equivalent to $\mathrm{MIC}, \mathrm{BrCl}$-flav significantly inhibited the growth of all clinical isolates $(p<0.05)$ for more than $24 \mathrm{~h}$ compared with control. The growth of Candida fluconazole-resistant strains was suppressed up to $48 \mathrm{~h}$ at $2 \times \mathrm{MIC}$, showing that BrCl-flav has an important fungistatic activity. The growth curves also revealed a progressive inhibition of the fungal growth by increasing the concentrations of the tested agent in the SDB medium. 

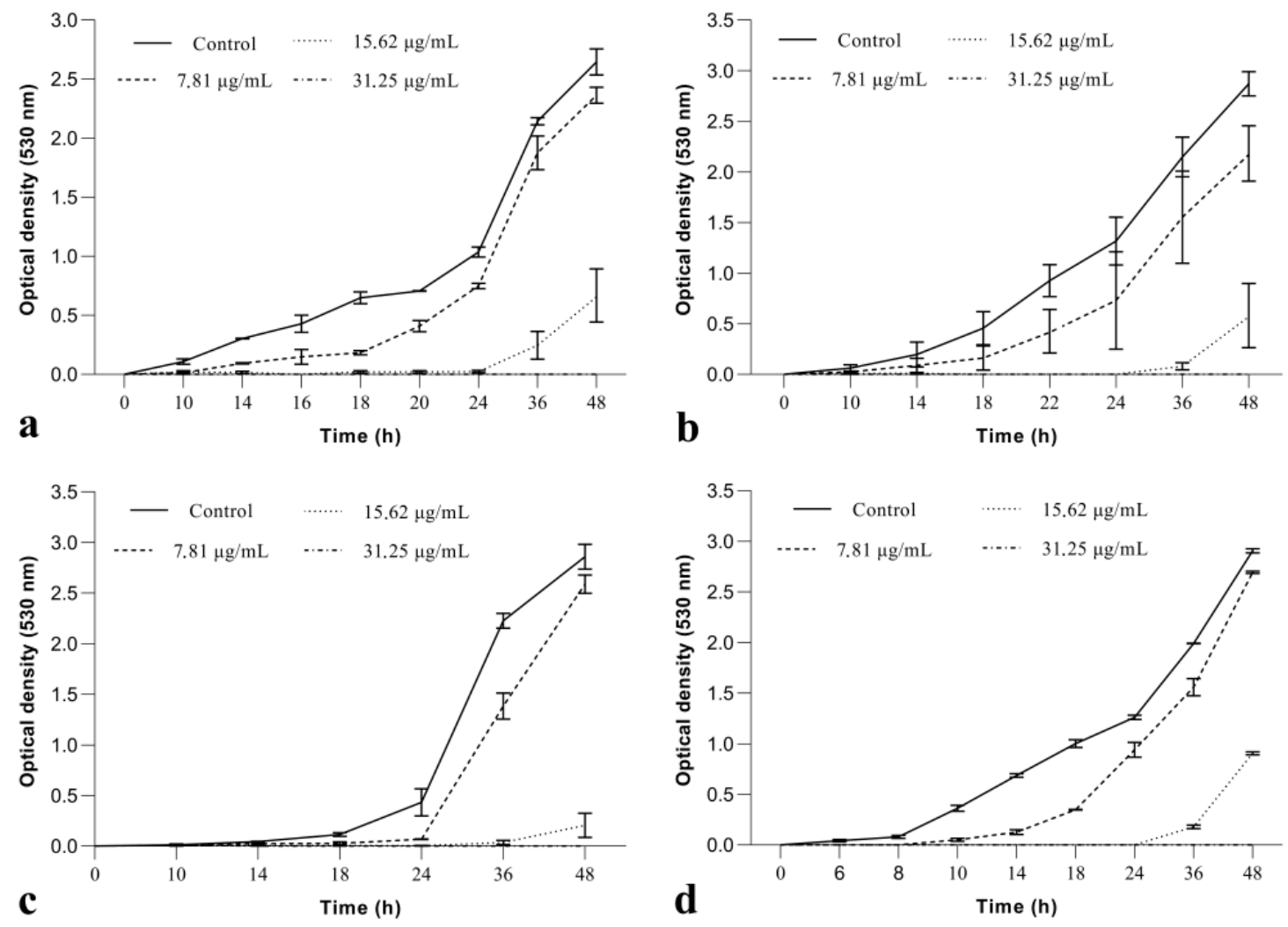

Figure 1. Growth kinetics of Candida spp. treated with BrCl-flav at different concentrations: (a) C. albicans; (b) C. krusei; (c) C. parapsilosis; (d) C. glabrata. Bars indicate standard deviations $(p<0.05)$.

\subsubsection{BrCl-Flav Has a Potent Fungicidal Activity against Candida spp.}

Time-kill assay showed a reduction in the number of viable Candida spp. cells for all $\mathrm{BrCl}$-flav tested concentrations (Figure 2). Thus, a significant reduction in microbial growth $(p<0.013)$ of $<3 \log 10$ in CFU / $\mathrm{mL}$ compared with the initial inoculum (considered as a fungistatic effect) was recorded when fungal cells were exposed more than $12 \mathrm{~h}$ to $\mathrm{BrCl}$-flav at concentrations equivalent to MIC. A fungicidal effect (a reduction in microbial growth of $\geq 3 \log 10 \mathrm{in} \mathrm{CFU} / \mathrm{mL}$ ) was evidenced after exposing Candida spp. cells to BrCl-flav concentrations equivalent to $2 \times \mathrm{MIC}$. Also, we must emphasize that BrCl-flav at $2 \times \mathrm{MIC}$ induced total kill (no viable cells) after only $12 \mathrm{~h}$ of incubation against fluconazole resistant strains (C. albicans, C. krusei) and C. parapsilosis strain, respectively.

\subsection{BrCl-Flav Mode of Action}

\subsubsection{Complexation of Sorbitol}

MIC values of $\mathrm{BrCl}$-flav did not change or were slightly lower (no statistically significant differences) in the presence of sorbitol, compared to BrCl-flav tested alone, as the results presented in Table 2 show. 

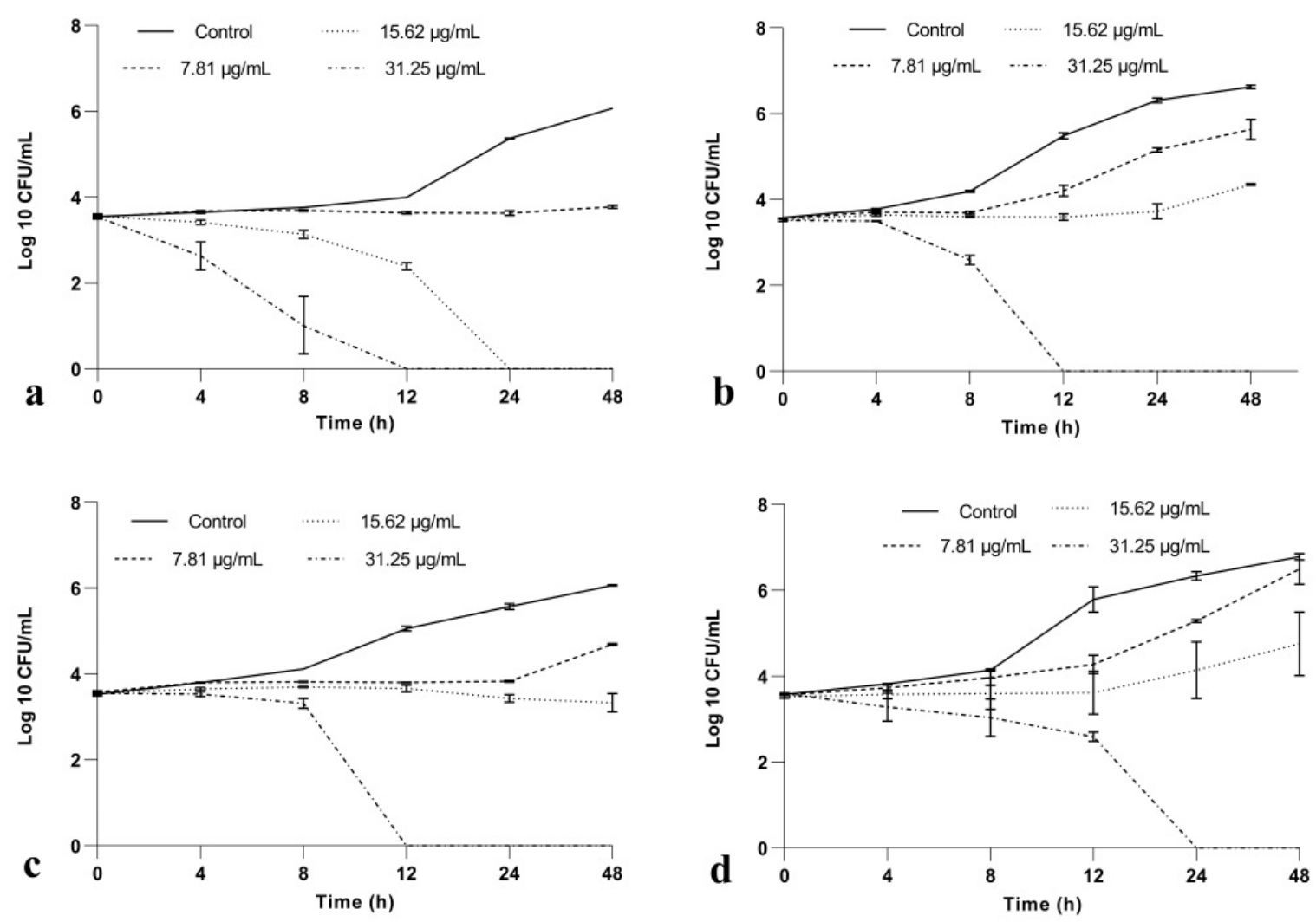

Figure 2. Time-kill curves after BrCl-flav exposure at different concentrations: (a) C. albicans; (b) C. krusei; (c) C. parapsilosis; (d) C. glabrata. Bars indicate standard deviations $(p<0.05)$.

Table 2. MIC values $(\mu \mathrm{g} / \mathrm{mL})$ of BrCl-flav in the absence and presence of sorbitol $(0.8 \mathrm{M})$ against tested Candida strains.

\begin{tabular}{ccc}
\hline \multirow{2}{*}{ Candida sp. Strains } & \multicolumn{2}{c}{ MIC $(\mu \mathrm{g} / \mathbf{m L})$} \\
\cline { 2 - 3 } & BrCl-Flav & BrCl-Flav + Sorbitol (0.8 M) \\
\hline C. albicans & 15.62 & 7.8 \\
C. parapsilosis & 15.62 & 7.8 \\
C. krusei & 15.62 & 15.62 \\
C. glabrata & 15.62 & 7.8 \\
\hline
\end{tabular}

$\overline{\mathrm{MIC}}=$ minimum inhibitory concentration; the values are mean for at least three replicates.

\subsubsection{Exposure to BrCl-Flav Caused Cellular Membrane Damage}

Penetration of PI into dead or injured C. albicans cells exposed to $\mathrm{BrCl}$-flav was evidenced using fluorescence microscopy. The number of fluorescent cells significantly increased in time in a dose dependent manner after $\mathrm{BrCl}$-flav treatment $(p<0.047)$ at concentrations equivalent to $2 \times \mathrm{MIC}$, starting with $4 \mathrm{~h}$ of incubation (Figure 3). After $48 \mathrm{~h}$ all $\mathrm{BrCl}$-flav exposed cells were fluorescent (Figure 4). Increasing the $\mathrm{BrCl}$-flav concentration to $5 \times$ MIC induced more significant membrane damage. Thus, after only $1 \mathrm{~h}$ of incubation, $75 \%$ of the C. albicans cells treated with $\mathrm{BrCl}-\mathrm{flav}$ were fluorescent and after $24 \mathrm{~h}$ of exposure the percentage increased to 100\%. No fluorescent cells were detected in control up to $48 \mathrm{~h}$, showing the inability of PI to penetrate viable cells with intact plasma membranes (Figure 3). 


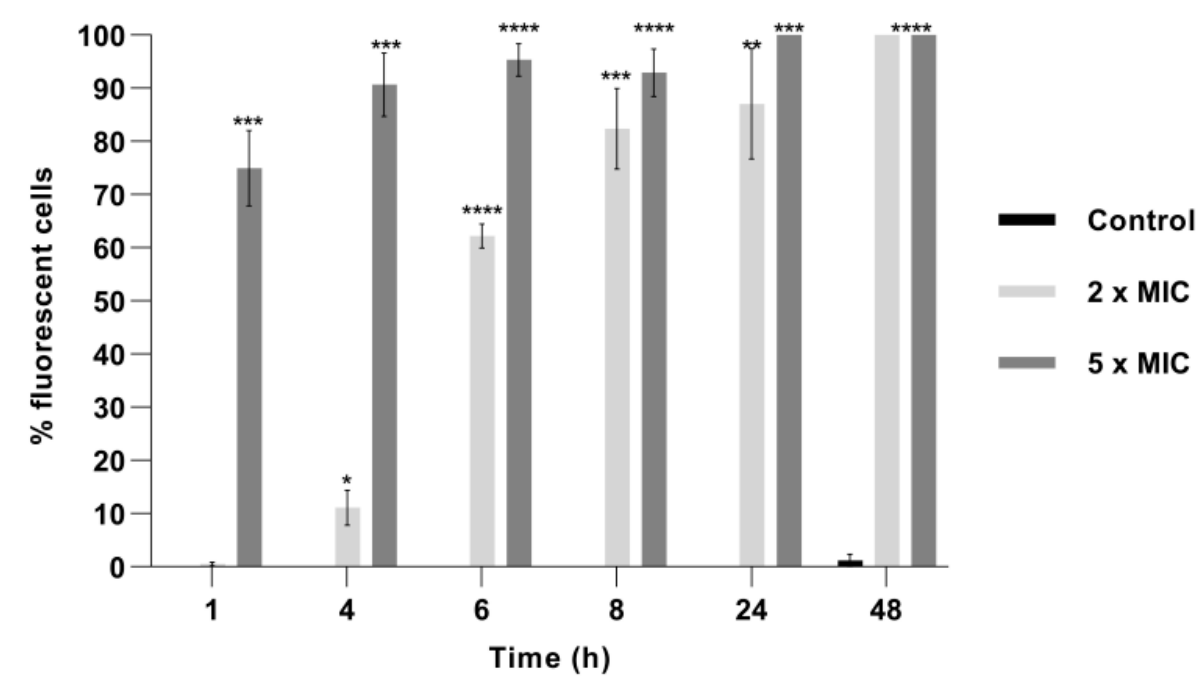

Figure 3. Effect of BrCl-flav on Candida albicans cell membrane structure. Cells were treated with concentrations of $\mathrm{BrCl}$-flav equivalent to $2 \times \mathrm{MIC}$ and $5 \times \mathrm{MIC}$ and stained with propidium iodide. Bars indicate standard deviations. Asterisk represents a significant difference $(p<0.05)$ vs. Control $\left(^{*}=p<0.0476 ;^{* *}=p<0.0019 ;{ }^{* * *}=p<0.0008 ;^{* * * *}=p<0.0001\right)$.

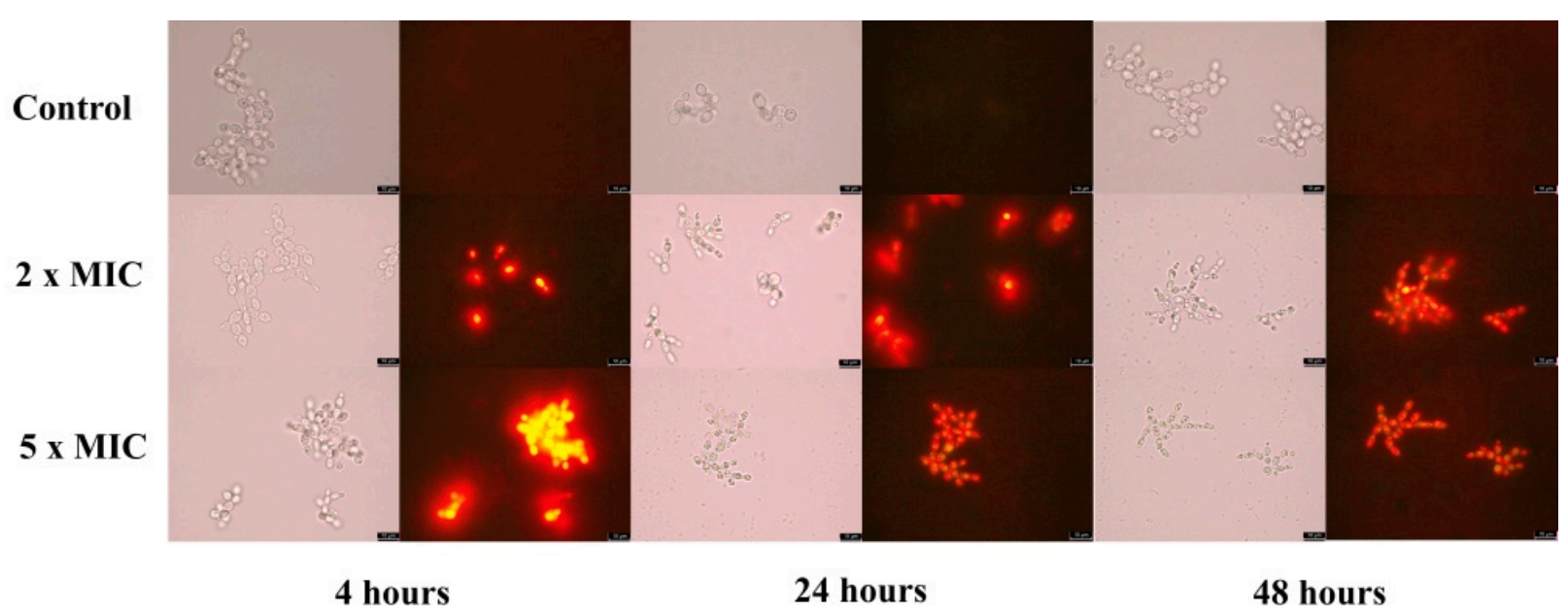

Figure 4. Effect of the BrCl-flav exposure on membrane permeability of Candida albicans exponential-phase cells to propidium iodide. Red fluorescence cells were detected in samples using fluorescence microscopy after 4, 24 and 48 h of incubation with BrCl-flav (concentrations equivalent to $2 \times \mathrm{MIC}$ and $5 \times \mathrm{MIC}$ ); magnification $1000 \times$.

\subsubsection{BrCl-Flav Induced Irreversible Morphological Damage}

Scanning electron microscopy was employed to assess the effect of $\mathrm{BrCl}-\mathrm{flav}$ on $\mathrm{C}$. albicans cell morphology. Control cells showed an intact morphology, with regular, smooth surface and a clear boundary (Figure 5a). The analysis of SEM photomicrographs pointed out that $\mathrm{BrCl}$-flav exposure resulted in considerable morphological damage of fungal cells compared with control, along with release of inner cell materials, most probably due to cell lysis and aglutination, as it can be seen in Figures $5 \mathrm{~b}-\mathrm{e}$ and $6 \mathrm{e}, \mathrm{f}$. 


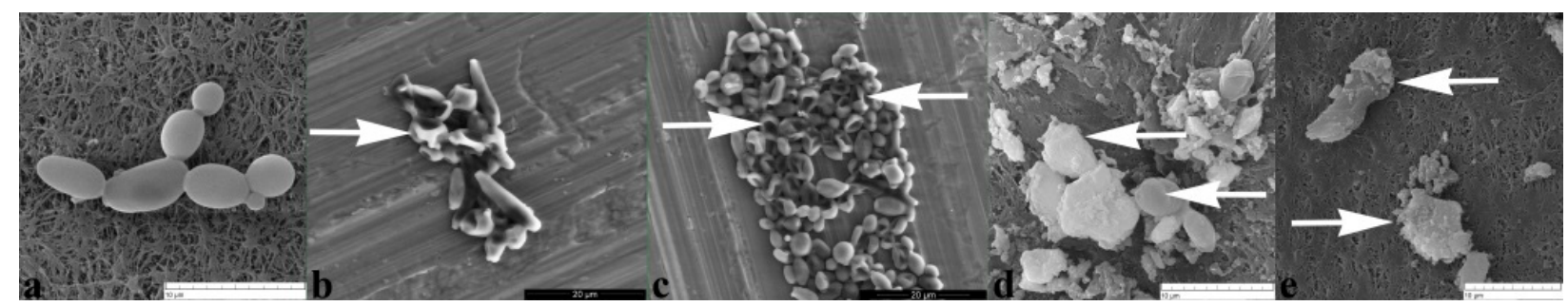

Figure 5. SEM photomicrographs showing the effects of BrCl-flav on Candida albicans cell morphology: (a) control; (b) cells exposed $6 \mathrm{~h}$ to MIC; (c) cells exposed $6 \mathrm{~h}$ to $2 \times \mathrm{MIC}$; (d) cells exposed $6 \mathrm{~h}$ to $5 \times \mathrm{MIC}$; (e) cellular debris. Arrows indicate irreversible morphological damage of treated fungal cells. These scanning electron photomicrographs are representative of a typical result.

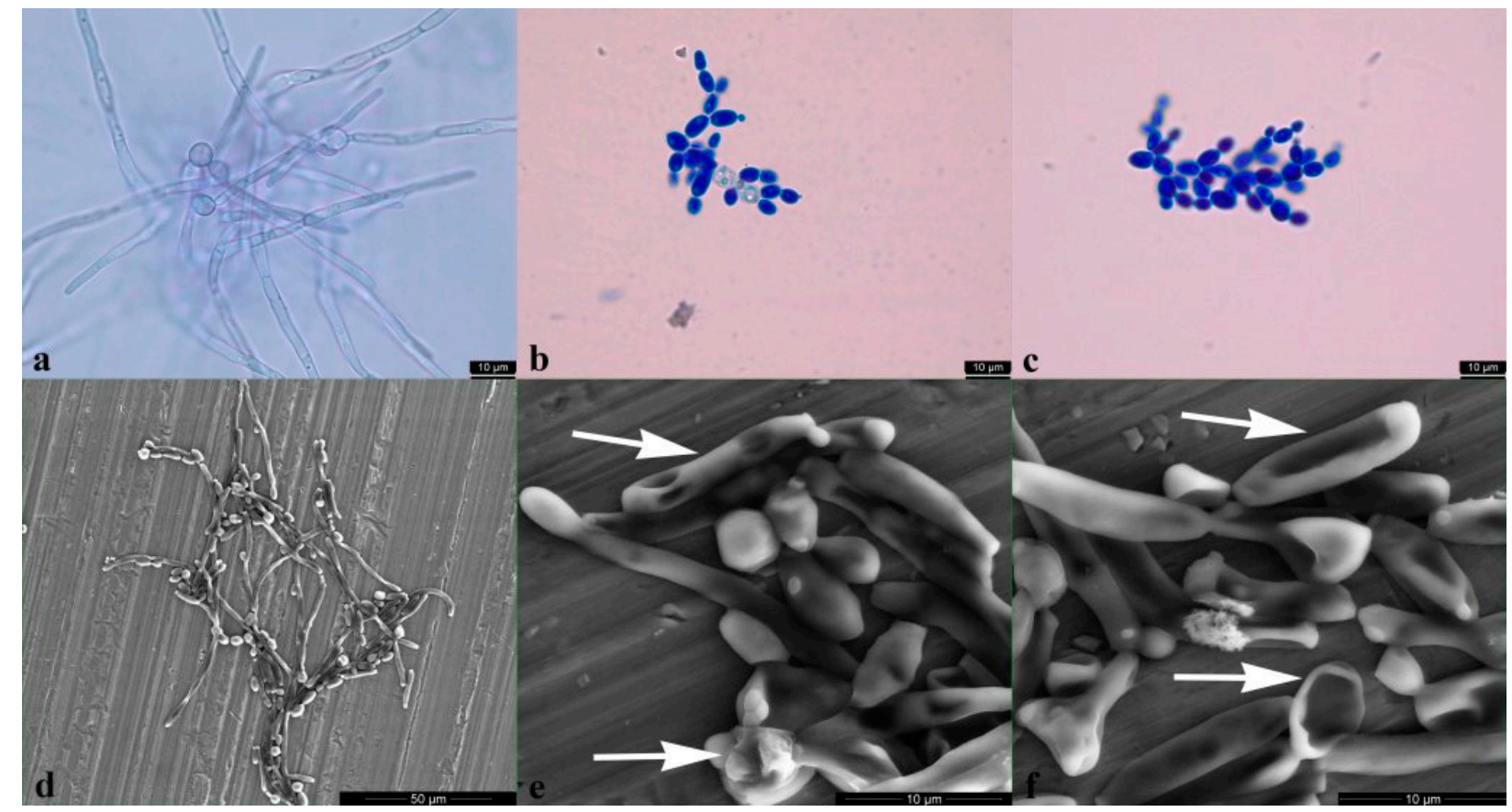

Figure 6. BrCl-flav inhibition of C. albicans hyphal formation in liquid RPMI $1640\left(6 \mathrm{~h}\right.$ at $\left.37{ }^{\circ} \mathrm{C}\right)$ : control cells (a,d); cell exposed to BrCl-flav at concentrations equivalent to $\mathrm{MIC}(\mathbf{b}, \mathbf{e})$ and $2 \times \mathrm{MIC}(\mathbf{c}, \mathbf{f})$; control cells formed hyphae (a,d); hyphae formation was inhibited by BrCl-flav at MIC (e); yeast to hyphal transition was prevented by BrCl-Flav at $2 \times \mathrm{MIC}$ equivalent concentration (c,f); treated cells appeared colored in blue when a methylene blue staining was performed to distinguish between live and dead cells $(\mathbf{b}, \mathbf{c})$ and showed significant morphological damages (e,f). Arrows indicate irreversible morphological damage of treated fungal cells. Images were obtained using a light microscope, magnification $1000 \times(\mathbf{a}-\mathbf{c})$ and SEM (d-f).

\subsubsection{Candida albicans Yeast to Hyphal Transition Was Prevented by BrCl-Flav}

The effect of BrCl-flav at concentrations equivalent to $\mathrm{MIC}$ and $2 \times \mathrm{MIC}$ on $\mathrm{C}$. albicans hyphal formation was evaluated using hypha-inducing conditions (incubation in RPMI 1640 medium). The results showed that BrCl-flav significantly inhibited yeast to hyphal transition starting with $6 \mathrm{~h}$ incubation time. We must emphasize that the treated cells did not formed hyphae in the presence of all tested BrCl-flav concentrations up to $48 \mathrm{~h}$ (data not shown), except for MIC samples for which the inhibition rate calculated at $6 \mathrm{~h}$ was $57.14 \%$. When a methylene blue staining was performed to distinguish between live and dead cells, all $2 \times$ MIC BrCl-flav exposed cells appeared colored in blue, being considered as dead (Figure $6 \mathrm{c}$ ). The BrCl-flav inhibition of hyphae formation was also confirmed by SEM. The photomicrograph presented in Figure $6 \mathrm{f}$ show both the absence of hyphae and 
irreversible morphological damage of fungal cells incubated in the presence of $\mathrm{BrCl}-\mathrm{flav}$ at concentrations equivalent to $2 \times \mathrm{MIC}$.

\subsubsection{BrCl-Flav Impedes Candida spp. Biofilm Formation}

Anti-biofilm activity was assessed against three Candida strains: C. albicans, C. krusei and C. glabrata. Our results showed that BrCl-flav had a significant inhibitory effect on biofilm formation for all tested strains, in a dose-dependent manner (Figure 7). A significant reduction in biofilm formation $(p<0.0030)$ up to $80 \%$ compared to control was evidenced at concentrations equivalent to MIC for C. albicans and C. krusei. Also, it should be noted that significant antibiofilm activity $(p<0.0088)$ was recorded for both strains at subinhibitory BrCl-flav concentrations (1/4 MIC and 1/2 MIC).
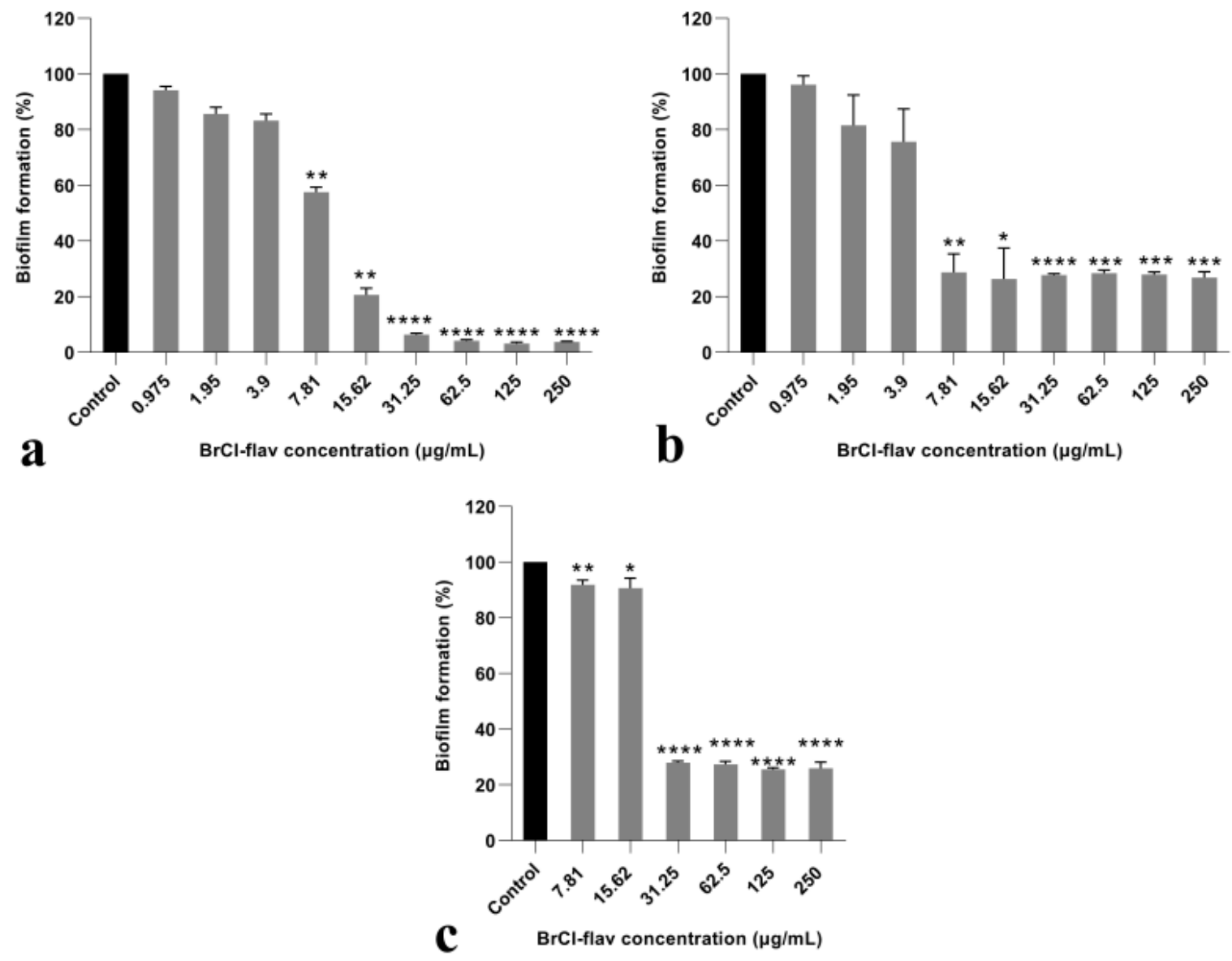

Figure 7. In vitro activities of BrCl-flav against Candida spp. biofilm formation: (a) C. albicans; (b) C. krusei; (c) C. glabrata. Bars indicate standard deviations. Asterisk represents a significant difference $(p<0.05)$ vs. Control $\left({ }^{*}=p<0.0435 ;{ }^{* *}=p<0.0088\right.$; $\left.* * *=p<0.0009 ;{ }^{* * * *}=p<0.0001\right)$.

\subsection{Effect of BrCl-Flav in Combination with Fluconazole against Candida Strains}

Assessment of the combination between BrCl-flav and fluconazole against Candida strains showed that the tested combinations produced synergistic, additive and indifferent interaction effects (Table 3).

The only synergistic interactions $(\mathrm{FICI} \leq 0.5)$ were recorded for $C$. albicans strain resistant to fluconazole. When used in combination, the MIC values of the two agents were reduced 128-fold for fluconazole and up to 8-fold for BrCl-flav. 
Table 3. Fractional inhibitory concentration indices (FICIs) of different $\mathrm{BrCl}$-flav-fluconazole combinations against Candida spp strains.

\begin{tabular}{|c|c|c|c|c|c|c|}
\hline \multirow{3}{*}{$\begin{array}{c}\text { Candida } \\
\text { sp. Strains }\end{array}$} & \multicolumn{4}{|c|}{$\operatorname{MIC}(\mu \mathrm{g} / \mathrm{mL})$} & \multirow{3}{*}{ FICI } & \multirow{3}{*}{ Interaction } \\
\hline & \multicolumn{2}{|c|}{ Alone } & \multicolumn{2}{|c|}{ In Combination } & & \\
\hline & BrCl-Flav & Fluconazole & BrCl-Flav & Fluconazole & & \\
\hline \multirow{4}{*}{ C. albicans } & \multirow{4}{*}{15.62} & \multirow{4}{*}{1000} & 15.62 & 0.16 & 1 & IND \\
\hline & & & 7.81 & 7.81 & 0.50 & SYN \\
\hline & & & 3.9 & 7.81 & 0.25 & SYN \\
\hline & & & 1.95 & 7.81 & 0.12 & SYN \\
\hline \multirow{4}{*}{ C. krusei } & \multirow{4}{*}{15.62} & \multirow{4}{*}{62.5} & 15.62 & 0.12 & 1 & IND \\
\hline & & & 7.81 & 31.25 & 1 & IND \\
\hline & & & 3.9 & 31.25 & 0.75 & ADD \\
\hline & & & 1.95 & 31.25 & 0.62 & ADD \\
\hline \multirow{4}{*}{$\begin{array}{c}\text { C. } \\
\text { parapsilosis }\end{array}$} & \multirow{4}{*}{15.62} & \multirow{4}{*}{3.9} & 15.62 & 0.12 & 1.03 & IND \\
\hline & & & 7.81 & 1.95 & 1 & IND \\
\hline & & & 3.9 & 1.95 & 0.75 & ADD \\
\hline & & & 1.95 & 3.9 & 1.12 & IND \\
\hline \multirow{4}{*}{ C. glabrata } & \multirow{4}{*}{15.62} & \multirow{4}{*}{125} & 15.62 & 31.25 & 1.25 & IND \\
\hline & & & 7.81 & 31.25 & 0.75 & ADD \\
\hline & & & 3.9 & 62.5 & 0.75 & ADD \\
\hline & & & 1.95 & 125 & 1.12 & IND \\
\hline
\end{tabular}

MIC: Minimum inhibitory concentration; SYN: synergy (FICI $\leq 0.5)$; ADD: additivity $(0.5<$ FICI $\leq 1)$; IND: indifference $(1<\mathrm{FICI} \leq 4)$; the values are mean for at least three replicates.

A combination of BrCl-flav and fluconazole $(3.9 / 7.81 \mu \mathrm{g} / \mathrm{mL})$ was further selected to study the synergistic effect over time, using a time-kill assay. No reduction in the number of viable Candida albicans cells was recorded for BrCl-flav and fluconazole used alone, compared with the control. However, when used in combination, the two tested antifungal agents showed a significant fungicidal activity $(p<0.0012)$, with total kill after $48 \mathrm{~h}$ (Figure 8).

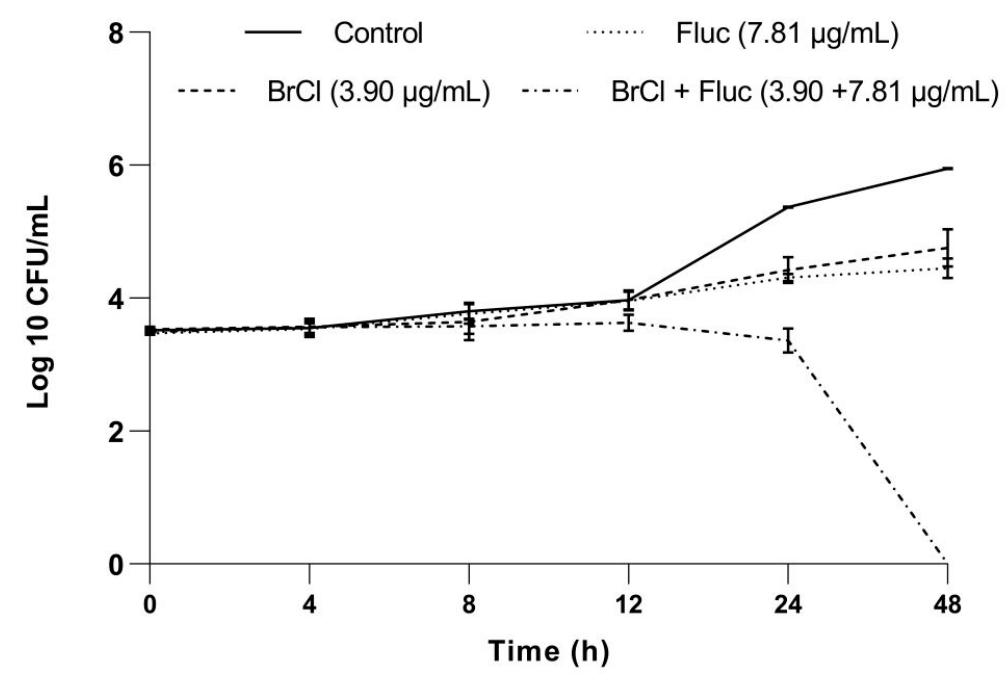

Figure 8. The time-kill curve of BrCl-flav and fluconazole synergistic combination against Candida albicans strain. Bars indicate standard deviations $(p<0.05)$. 


\section{Discussion}

Infections caused by fungi like Candida are very difficult to treat due to increasing antifungal resistance. Recent studies showed that patients with Candida infections resistant to fluconazole have in fact very few treatment options (US Centers for Disease Control and Prevention, https:/ / www.cdc.gov/fungal/diseases/candidiasis/antifungal-resistant.html (accessed on 3 November 2021)). Moreover, patients who have drug-resistant Candida bloodstream infections are less likely to survive than patients who have infections caused by drug-sensitive Candida strains $[12,13]$. Therefore, finding new efficient, low toxicity antifungal agents is a matter of medical high priority.

$\mathrm{BrCl}-\mathrm{flav}$ is a synthetic tricyclic flavonoid representative for a novel class of sulfur containing flavonoids easy and simple to obtain in a cost-effective manner. We previously showed that this compound has a remarkable antibacterial activity at low concentrations: $0.24 \mu \mathrm{g} / \mathrm{mL}$ against Staphylococcus aureus and $3.9 \mu \mathrm{g} / \mathrm{mL}$ against Escherichia coli [11]. The main mechanism responsible for the bactericidal effects is related to the impairment of the cell membrane integrity and cell lysis. As such, we have strong reasons to consider that $\mathrm{BrCl}$-flav has a good potential for the development of new antimicrobial agents. Therefore, further studies using four clinical Candida isolates were employed to investigate BrCl-flav antifungal properties and mechanism of action.

A potent antifungal effect was evidenced for BrCl-flav against all Candida strains tested in vitro using the determination of minimum inhibitory concentration. The method allowed us to assess the lowest concentration of $\mathrm{BrCl}$-flav which inhibited the growth of the tested fungal strains $-15.62 \mu \mathrm{g} / \mathrm{mL}$. When compared with the reference drug fluconazole, a considerable higher antifungal activity was recorded against fluconazole resistant $C$. albicans, C. krusei and C. glabrata isolates. Compared to most of the reported natural and synthetic flavonoids, our compound displayed a stronger antifungal activity, being up to 28-fold more active against Candida spp. (e.g., baicalein-MIC up to $21 \mu \mathrm{g} / \mathrm{mL}$; myricetinMIC up to $64 \mu \mathrm{g} / \mathrm{mL}$; quercetin-MIC up to $441 \mathrm{mg} / \mathrm{mL}$, etc) - $[7,14,15]$. We must emphasize that $\mathrm{BrCl}$-flav exhibited an antifungal activity comparable to some chalcone, flavones and flavanones derivatives considered to be the most potent synthetic flavonoids against Candida reported so far (MIC values ranging from 1 to $16 \mu \mathrm{g} / \mathrm{mL}$ ) - [7].

The same important antifungal activity of BrCl-flav was evidenced by the growth kinetics studies. The fungistatic effect was dose-dependent, increasing concentrations of $\mathrm{BrCl}$-flav progressively inhibited the fungal growth of all tested Candida isolates. The cells incubated with $7.81 \mu \mathrm{g} / \mathrm{mL} \mathrm{BrCl-flav}$ (concentration equivalent to 1/2 MIC) showed no significant growth inhibition compared with control. On the other hand, a significant growth delay (up to $28 \mathrm{~h}$ ) represented by prolonged lag phases occurred when Candida spp. cells were incubated in the presence of BrCl-flav at $15.2 \mu \mathrm{g} / \mathrm{mL}$, corresponding to MIC. We must point out that no turbidity was recorded by spectrophotometric measurements for all Candida cells exposed to $31.25 \mu \mathrm{g} / \mathrm{mL}$ within the time span of the experiments $(48 \mathrm{~h}$ ), denoting a strong fungicidal activity.

A time-kill kinetics assay was employed to determine the fungistatic or fungicidal activity of BrCl-flav over time. The analysis confirmed also the important antifungal activity of BrCl-flav against all Candida spp. after exposure to concentrations equivalent to MIC (fungistatic effect) and $2 \times$ MIC (fungicidal effect). One exception occurred for C. albicans strain - a fungistatic effect was recorded by the growth experiments up to $24 \mathrm{~h}$, while time kill studies revealed a fungicidal effect (99.9\% killing of cells) at $24 \mathrm{~h}$. A reasonable explanation could be related to different experimental conditions used for the two assays. We must emphasize that no viable cells (total kill) were detected starting with $12 \mathrm{~h}$ after BrCl-flav exposure at $31.25 \mu \mathrm{g} / \mathrm{mL}$ (equivalent to $2 \times \mathrm{MIC}$ ), suggesting an important fungicidal potential. The fact that this activity has been recorded against fluconazole-resistant Candida strains makes BrCl-flav a more interesting compound for practical applications. Our conclusion is supported by a comparative literature survey which revealed that $\mathrm{BrCl}$-flav has higher fungicidal activity (up to 48-times) compared to many natural flavonoids [16-18]. Also, the recorded activity was higher or comparable 
with other synthetic flavonoids such as different chalcone, 1,3-thiazole and 2-hydrazinyl1,3-thiazole derivatives [8,19-21]. We must emphasize that $\mathrm{BrCl}$-flav acted as a more potent fungicidal compared with fluconazole, considered to be a gold standard of antifungal agents [22].

Sorbitol binding affinity assay (MIC determination in the presence and absence of $0.8 \mathrm{M}$ sorbitol) was used to investigate the interference of $\mathrm{BrCl}$-flav with the Candida cell wall. Sorbitol is an osmotic protector which can support cell growth when the fungal wall is targeted by antifungal agents. In the absence of sorbitol, the fungal growth is inhibited due to the disruption of the cell wall. The effect is detected by an increase of the MIC value in the presence of sorbitol compared to the MIC value determined in medium without sorbitol. [23]. In our study, MIC values of BrCl-flav did not change in the presence of sorbitol, suggesting that the tested synthetic flavonoid does not target the cell wall. Therefore, other potential cellular targets were investigated. Penetration of PI into dead or injured $C$. albicans cells was evidenced using fluorescence microscopy. PI is a cell membrane-selective permeable dye that can only pass through damaged or permeabilized cell membranes, binding to DNA and exhibiting characteristic red fluorescence [24]. Our results revealed a gradual increase of the fluorescent cells number with the increasing concentration of the tested antifungal. After $24 \mathrm{~h}$ all cells exposed to $\mathrm{BrCl}$-flav at a concentration equivalent to $5 \times$ MIC were fluorescent, suggesting that the tested antifungal significantly damaged the fungal cell membrane integrity. Usually, damages to the cell membrane are related to cell lysis. SEM image analysis showed severe alteration of the cell morphology, with collapsed cells, wrinkled surfaces, along with cellular debris resulting from the disintegration of the $\mathrm{BrCl}$-flav treated cells. These morphological changes are most likely caused by cell lysis. All those results clearly indicate that the main BrCl-flav mechanism of action is related to membrane disruption followed by cell lysis.

Hyphae and biofilm formation-two critical virulence factor of $C$. albicans-were investigated to better understand how $\mathrm{BrCl}$-flav affects fungal cells. Both Candida virulence attributes are interlinked, contributing not only to the host tissue invasion but also to the evasion of host immunity [17]. Our study revealed that BrCl-flav prevented both yeast to hyphal transition and biofilm formation. The effect was concentration dependent, increasing $\mathrm{BrCl}$-flav concentrations resulting in an increased inhibitory activity. Moreover, the tested antifungal impaired plasma membrane organization, a cell structure which promotes also the virulence of the human fungal pathogen C. albicans [25] highlighting $\mathrm{BrCl}$-flav therapeutic potential.

Biofilm formation also contributes to Candida antifungal resistance-a major problem faced by modern medicine. One solution could be the use of synergistic combinations of new molecules with traditional antifungals used in therapy to which Candida strains have already become resistant. Flavonoids in combination with fluconazole have been shown to display remarkable synergistic antifungal effects and are considered as reliable compounds for antifungal drug research and development [7]. In our study which involved a fluconazole resistant $C$. albicans clinical isolate, the MIC of fluconazole was 128-fold reduced in combination with $\mathrm{BrCl}$-flav (concentrations ranging from 1.95 to $7.81 \mu \mathrm{g} / \mathrm{mL}$ ), suggesting an important synergistic antifungal activity. We have to emphasize also that a combination of BrCl-flav and fluconazole in lower concentrations compared with individual MIC values showed important fungicidal effect with total kill after $48 \mathrm{~h}$ of incubation.

\section{Materials and Methods}

\subsection{Chemicals and Fungal Strains}

Tricyclic flavonoid BrCl-flav (Figure 9) was obtained as previously described [26]. The structure and purity ( $>99 \%$ ) of the final compound have been established by NMR, MS, IR and elemental analysis. UV-Vis spectroscopy was employed to monitor the stability of BrCl-flav towards Sabouraud dextrose broth (SDB, Carl Roth, Karlsruhe, Germany), RPMI 1640 (Carl Roth) and phosphate buffer saline (PBS). The tricyclic flavonoid proved to be stable over a time span equivalent to the performed tests. 


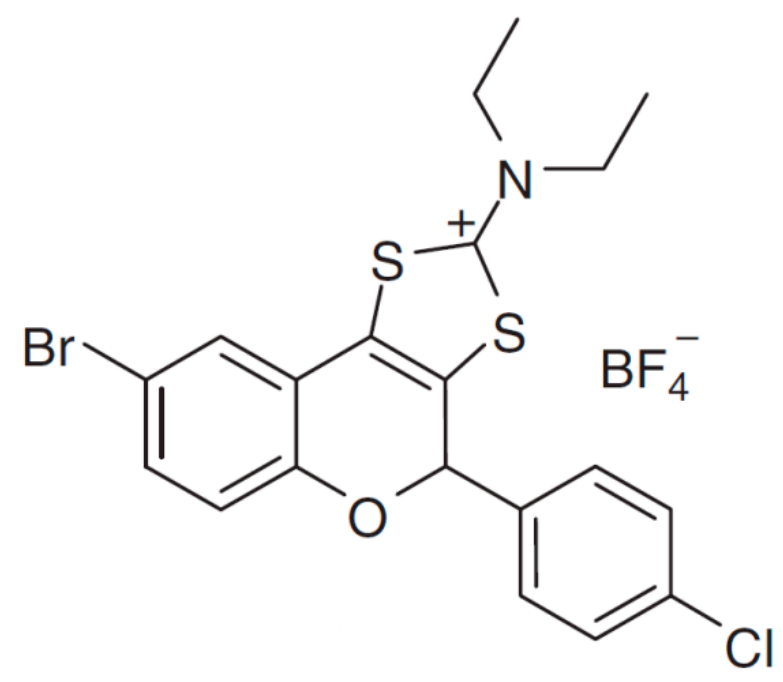

Figure 9. Structure of flavonoid BrCl-flav.

Candida albicans, C. parapsilosis and C. krusei were kindly provided by Dr Simona Matiut from the Praxis Clinical Laboratory (Iasi, Romania). C. glabrata strain was kindly provided by Dr M.N.L. Ngo-Mback (Laboratory for Phytobiochemistry and Medicinal Plants Studies, University of Yaounde I, Yaounde, Cameroon). The fungal strains were included in the microbial culture collection of the Faculty of Biology, University Alexandru Ioan Cuza of Iasi, with the following accession numbers: prxhif1-2018 (C. albicans), prx32018 (C. parapsilosis), prxbiof2-2018 (C. krusei) and cambio5-2017 (C. glabrata). Candida krusei (ATCC 6258) was used as reference strain for control. All clinical isolates were stored in $15 \%$ glycerol stocks at $-80^{\circ} \mathrm{C}$. Prior to experiments, the organisms were transferred on Sabouraud dextrose agar (SDA, Carl Roth) and incubated $24 \mathrm{~h}$ at $37^{\circ} \mathrm{C}$. Subsequently, $15 \mathrm{~mL}$ of SDB were inoculated with one representative colony taken from SDA, cultured for $24 \mathrm{~h}\left(37^{\circ} \mathrm{C}, 130 \mathrm{rpm}\right)$ and used as source of inoculum for each experiment.

\subsection{Assessment of Antifungal Activity}

4.2.1. Determination of Minimum Inhibitory Concentration (MIC) and Minimum Fungicidal Concentration (MFC)

The MIC values were determined by the broth microdilution method, in accordance with [6]. A concentration range of BrCl-flav between 0.12-250 $\mu \mathrm{g} / \mathrm{mL}$ was tested with dimethyl sulfoxide (DMSO, Merck, Darmstadt, Germany) as solvent. DMSO was used as control with concentrations ranging from 25 to $0.012 \%(v / v)$ and nystatin as reference antifungal. Candida krusei ATCC 6258 was used as control strain. The inoculum was added into each well of a microplate (approximately $2.5 \times 10^{3} \mathrm{CFU} / \mathrm{mL}$ final cell density), except the wells containing only SDB medium considered as blank. Inoculum and SDB medium were used as growth control. The lowest concentration showing no visible growth was considered as the MIC. A volume of $15 \mu \mathrm{L}$ taken from each well with no visible growth was inoculated further on SDA to evaluate MFC. The MFC was considered the lowest concentration at which yeasts failed to grow in SDB supplemented with BrCl-flav and inhibited growth of the yeast after plating onto SDA [27].

\subsubsection{Fungal Growth Analysis}

Effect of BrCl-flav on Candida spp. growth was assessed as we previously described [28], with some modifications. A volume of $100 \mu \mathrm{L}$ from an overnight preculture was used to inoculate $20 \mathrm{ml}$ SDB (final cell density approximately $2.5 \times 10^{3} \mathrm{CFU} / \mathrm{mL}$ ). In order to test fungistatic activity over time and to check the minimum inhibitory concentration values, the medium was supplemented with $\mathrm{BrCl}$-flav to obtain final concentrations equivalent with $1 / 2$ MIC, MIC, $2 \times$ MIC. Inoculated SDB medium supplemented with DMSO without BrCl-flav 
at appropriate concentrations was used as control. All flasks were incubated on an orbital shaker $(130 \mathrm{rpm})$ at $37^{\circ} \mathrm{C}$ for $48 \mathrm{~h}$. Samples were taken and growth rates were determined by measuring the optical density at $530 \mathrm{~nm}$ (OD530), using a DU 730 spectrophotometer (Beckman Coulter, Brea, CA, USA).

\subsubsection{Time-Kill Kinetic Assay}

The killing rate of $\mathrm{BrCl}-\mathrm{flav}$ was determined by measuring the reduction in the number of colony-forming units (CFU) per mL using the method of counting viable cells [29]. A volume of $100 \mu \mathrm{L}$ from an overnight culture was added to $10 \mathrm{~mL}$ PBS (final cell density approximately $2.5 \times 10^{3} \mathrm{CFU} / \mathrm{mL}$ ) with various concentrations of BrCl-flav (1/2 MIC, MIC, $2 \times$ MIC). Controls were prepared similarly using DMSO at appropriate concentrations. All flasks were incubated for $48 \mathrm{~h}$ at $37^{\circ} \mathrm{C}$. Samples were removed every $4 \mathrm{~h}$ up to $12 \mathrm{~h}$ and at $24,48 \mathrm{~h}$, serially diluted, inoculated onto SDA culture medium and incubated at $37^{\circ} \mathrm{C}$. Colonies were counted after $24 \mathrm{~h}$ and the viable cell number reported as CFU per $\mathrm{mL}$ was transformed into log10 values. The results were represented graphically obtaining a microbial death curve as a function of time. Fungicidal activity of BrCl-flav was considered when a reduction in microbial growth of $\geq 3 \log 10$ in CFU $/ \mathrm{mL}$ was recorded compared with the initial inoculum (99.9\% killing of cells). Fungistatic activity was considered as a reduction in growth $<3 \log 10$ in CFU / $\mathrm{mL}$ from the initial inoculum (lower than 99.9\%).

\subsection{Sorbitol Binding Affinity Assay}

The interference of BrCl-flav with the cell wall was assessed using the microdilution method presented above for determination of MIC. The MIC was recorded in the absence and presence of $0.8 \mathrm{M}$ sorbitol after $48 \mathrm{~h}$ and it was considered as the lowest concentration at which no visible growth was observed [6].

\subsection{Cell Membrane Permeability Test}

The procedure described by Ma et al. [24] was used to analyze the fungal cell membrane permeability, with some modifications. C. albicans cells from an overnight culture were washed and suspended in PBS. The cell suspension (final cell density approximately $\left.1 \times 10^{6} \mathrm{CFU} / \mathrm{mL}\right)$ was incubated at $37^{\circ} \mathrm{C}$ on an orbital shaker $(130 \mathrm{rpm})$ for $48 \mathrm{~h}$ in presence of BrCl-flav at a concentration equivalent to $\mathrm{MFC}$ value $(31.25 \mu \mathrm{g} / \mathrm{mL})$. In order to observe a possible dose dependent effect of BrCl-flav against membrane structure, a higher concentration was also used $(71.8 \mu \mathrm{g} / \mathrm{mL}$ - equivalent to $5 \times \mathrm{MIC})$. Cells in PBS supplemented with DMSO served as control. Samples were taken at 1, 4, 6, 8, 24 and $48 \mathrm{~h}$ and stained with propidium iodide (PI, Carl Roth) for $15 \mathrm{~min}$ in the dark. The fluorescent cells were counted using a DM1000 LED fluorescence microscope (Leica, Wetzlar, Germany) and a I3 blue excitation range filter cube (BP $450 \pm 490 \mathrm{~nm}$ band pass filter). At least five random, independent images were captured per sample and the ratio between fluorescent cells and total cells was calculated as percentage.

\subsection{Hyphal Growth Test}

Yeast to hyphal transition was performed following the procedure described by Wang et al. [30]. C. albicans cells from an overnight culture were incubated in RPMI 1640 at $37^{\circ} \mathrm{C}$ in the presence of different BrCl-flav concentrations (MIC and $2 \times \mathrm{MIC}$ ). Inoculated RPMI 1640 without flavonoid and supplemented with DMSO was used as control. Samples were taken at $6,8,10,12,24$, and $48 \mathrm{~h}$ after inoculation and a simple staining using methylene blue (Sigma-Aldrich, Darmstadtcity, Germany) to distinguish between live and dead cells has been performed [31]. Yeast to hyphal transition was evaluated by microscopic observation using a Leica DM1000 LED microscope and scanning electron microscopy (Quanta 450, FEI, Thermo Fisher Scientific, Waltham, MA, USA). At least five random, independent images were captured per sample and used to count the number of individual yeast cells versus the number of hyphae. The hyphae inhibition rate (\%) was calculated using the following Equation (1): 
Hyphae inhibition rate $=($ hyphae $\%$ control - hyphae $\%$ BrCl-flav $) /$ hyphae $\%$ control $\times 100$

\subsection{Scanning Electron Microscopy (SEM)}

C. albicans cell morphology after BrC-flav treatment was evaluated using SEM method, as we previously described [11]. An overnight culture was washed, centrifuged, suspended in PBS and incubated for $6 \mathrm{~h}$ in the presence of BrCl-flav at different concentrations (MIC, $2 \times$ MIC and $5 \times$ MIC) and DMSO as control. The samples were examined by SEM (Vega II $\mathrm{SBH}$, Tescan, Brno, Czech Republic) at an acceleration voltage of $27.88 \mathrm{kV}$. Yeast to hyphal transition was investigated using a SEM system working in environmental mode (Quanta 450, FEI, Thermo Fisher Scientific, Waltham, MA, USA). The device is designed to be used with biological samples without the need to cover them with a conductive layer. The analyses were performed in low vacuum mode (at $100 \mathrm{~Pa}$ ) in pure water vapor atmosphere with an electron acceleration voltage of $10 \mathrm{kV}$.

\subsection{In Vitro Anti-Biofilm Activity Assay}

The effect of BrCl-flav on C. albicans, C. krusei and C. glabrata biofilm-forming ability was determined as previously described [6]. Briefly, $250 \mu \mathrm{L}$ of a cell suspension $\left(1 \times 10^{3} \mathrm{CFU} / \mathrm{mL}\right)$ in SDB was added into each well of a microtiter plate. The medium was supplemented with $6 \%$ of glucose and incubated at $37^{\circ} \mathrm{C}$ for $48 \mathrm{~h}$ in presence of various concentrations of BrCl-flav. The wells containing only inoculated SDB supplemented with DMSO served as control. After an initial $6 \mathrm{~h}$ incubation, the culture medium was carefully removed and washed with distilled water to remove non-attached cells. A fresh medium was added and incubated to allow biofilm formation. After incubation, the wells were washed with distilled water to remove planktonic cells and crystal violet (Carl Roth) staining was performed [32]. A Beckman Coulter spectrophotometer was used to determine the optical densities (ODs) at a wavelength of $590 \mathrm{~nm}$. Biofilm formation in the presence of $\mathrm{BrCl}$-flav was expressed as a percentage of the control biofilm incubated in the absence of BrCl-flav (considered as 100\%).

\subsection{Checkerboard Assay}

The effect of BrCl-flav in combination with fluconazole against Candida spp. resistant strains was assessed using the checkerboard microdilution method [6]. Two 96-well plates were used to obtain serial two-fold dilutions of the tested antifungal agents: the first microplate was used to dilute $\mathrm{BrCl}$-flav in horizontal orientation and the second one was used to make dilutions of fluconazole in vertical orientation. The used concentrations of the tested antifungals were selected based on MIC values previously determined. All dilutions were made in SDB medium (50 $\mu \mathrm{L}$ per well). Fluconazole dilutions $(50 \mu \mathrm{L})$ were transferred to the first plate to obtain different combinations of concentration with $\mathrm{BrCl}$-flav. Subsequently, $100 \mu \mathrm{L}$ of fungal suspension was added to each well (final cell density approximatively $10^{3} \mathrm{CFU} / \mathrm{mL}$ ). SDB medium and inoculum served as control. The yeast growth was assessed visually after microplates incubation at $37^{\circ} \mathrm{C}$ for $48 \mathrm{~h}$. The lowest concentration showing no visible growth was considered as the MIC. To evaluate the synergistic effect, the fractional inhibitory concentration index (FICI) was calculated for each combination (Equation (2)):

$$
\mathrm{FICI}_{\mathrm{AB}}=\mathrm{FIC}_{\mathrm{A}}+\mathrm{FIC}_{\mathrm{B}}
$$

The Fractional Inhibitory Concentration (FIC) of each agent (A or B) was calculated as a ratio of MIC when used in combination and MIC when used alone. FICI results for each combination $(\mathrm{AB})$ were defined as synergy for $\mathrm{FICI} \leq 0.5$, additivity for $0.5<\mathrm{FICI} \leq 1$, indifference for $1<$ FICI $\leq 4$ and antagonism for FICI $>4$. The effect of selected synergistic combinations was further assessed by time-killing curves. 


\subsection{Statistical Analysis}

All experiments were performed in triplicate. The data are presented as mean $(n=3)$ \pm S.E.M. The statistical evaluation of the results was carried out by Dunnett's multiple comparisons test using the GraphPad Prism 9 software (GraphPad Software, Inc., La Jolla, CA, USA ). Differences between groups were considered significant when $p<0.05$.

\section{Conclusions}

$\mathrm{BrCl}$-flav is a synthetic flavonoid with an important fungicidal activity against Candida albicans, C. parapsilosis, C. krusei and C. glabrata clinical isolates at low concentrations. Our compound expressed synergic antifungal activity in combination with fluconazole and anti-virulence properties against Candida spp., inhibiting biofilm formation and yeast to hyphal transition. The mechanism of action is related to its ability to induce cell lysis by impairing cell membrane permeability and integrity. Taken together, these findings suggest that $\mathrm{BrCl}$-flav has a considerable anti-Candida potential. Further studies are necessary to develop new antifungal drugs based on BrCl-flav.

Author Contributions: Conceptualization, M.S. (Marius Stefan) and L.M.B.; methodology, M.S. (Marius Stefan) and C.B.; validation, M.S. (Marius Stefan), L.M.B. and L.G.S.; formal analysis, M.S. (Mihaela Savu) and C.B.; investigation, C.B., M.S. (Mihaela Savu), I.M.; resources, M.S. (Marius Stefan), I.M. and L.M.B.; writing—original draft preparation, M.S. (Marius Stefan); writing—review and editing, M.S. (Marius Stefan) and L.G.S.; visualization, M.S. (Marius Stefan); supervision, M.S. (Marius Stefan); project administration, M.S. (Marius Stefan) and L.M.B.; funding acquisition, M.S. (Marius Stefan). All authors have read and agreed to the published version of the manuscript.

Funding: This work was supported by a grant of the Romanian Ministry of Education and Research, CCCDI-UEFISCDI, project number PN-III-P2-2.1-PED-2019-2235 (550PED/2020), within PNCDI III.

Institutional Review Board Statement: Not applicable.

Informed Consent Statement: Not applicable.

Data Availability Statement: Data is contained in the article.

Acknowledgments: The authors are grateful to biol. Stefan Mihaita Olaru (Electron Microscopy Laboratory, Faculty of Biology, UAIC Iasi) for his expertise and assistance throughout sample SEM analysis.

Conflicts of Interest: The authors declare no conflict of interest.

\section{References}

1. de Oliveira Santos, G.C.; Vasconcelos, C.C.; Lopes, A.J.O.; de Sousa Cartágenes, M.d.S.; Filho, A.K.D.B.; do Nascimento, F.R.F.; Ramos, R.M.; Pires, E.R.R.B.; de Andrade, M.S.; Rocha, F.M.G.; et al. Candida Infections and therapeutic strategies: Mechanisms of action for traditional and alternative agents. Front. Microbiol. 2018, 9, 1351. [CrossRef]

2. Tobudic, S.; Kratzer, C.; Lassnigg, A.; Presterl, E. Antifungal susceptibility of Candida albicans in biofilms. Mycoses 2012, 55, 199-204. [CrossRef] [PubMed]

3. Barchiesi, F.; Orsetti, E.; Osimani, P.; Catassi, C.; Santelli, F.; Manso, E. Factors Related to outcome of bloodstream infections due to Candida parapsilosis complex. BMC Infect. Dis. 2016, 16, 387. [CrossRef]

4. Pappas, P.G.; Kauffman, C.A.; Andes, D.R.; Clancy, C.J;; Marr, K.A.; Ostrosky-Zeichner, L.; Reboli, A.C.; Schuster, M.G.; Vazquez, J.A.; Walsh, T.J.; et al. Clinical Practice guideline for the management of candidiasis: 2016 update by the Infectious Diseases Society of America. Clin. Infect. Dis. 2015, 62, e1-e50. [CrossRef] [PubMed]

5. Douglas, L.J. Candida biofilms and their role in infection. Trends. Microbiol. 2003, 11, 30-36. [CrossRef]

6. Ngo-Mback, M.N.L.; Babii, C.; Jazet Dongmo, P.M.; Kouipou Toghueo, M.R.; Stefan, M.; Fekam Boyom, F. Anticandidal and synergistic effect of essential oil fractions from three aromatic plants used in Cameroon. J. Mycol. Med. 2020, 30, 100940. [CrossRef]

7. Jin, Y.-S. Recent advances in natural antifungal flavonoids and their derivatives. Bioorg. Med. Chem. Lett. 2019, $29,126589$. [CrossRef]

8. Sarbu, L.G.; Bahrin, L.G.; Babii, C.; Stefan, M.; Birsa, M.L. Synthetic flavonoids with antimicrobial activity: A review. J. Appl. Microbiol. 2019, 127, 1282-1290. [CrossRef]

9. Panche, A.N.; Diwan, A.D.; Chandra, S.R. Flavonoids: An overview. J. Nutr. Sci. 2016, 5, e47. [CrossRef]

10. Sagrera, G.; Bertucci, A.; Vazquez, A.; Seoane, G. Synthesis and antifungal activities of natural and synthetic biflavonoids. Bioorg. Med. Chem. 2011, 19, 3060-3073. [CrossRef] 
11. Babii, C.; Bahrin, L.G.; Neagu, A.N.; Gostin, I.; Mihasan, M.; Birsa, L.M.; Stefan, M. Antibacterial activity and proposed action mechanism of a new class of synthetic tricyclic flavonoids. J. Appl. Microbiol. 2016, 120, 630-637. [CrossRef]

12. Alexander, B.D.; Johnson, M.D.; Pfeiffer, C.D.; Jiménez-Ortigosa, C.; Catania, J.; Booker, R.; Castanheira, M.; Messer, S.A.; Perlin, D.S.; Pfaller, M.A. Increasing echinocandin resistance in Candida glabrata: Clinical failure correlates with presence of fks mutations and elevated minimum inhibitory concentrations. Clin. Infect. Dis. 2013, 56, 1724-1732. [CrossRef] [PubMed]

13. Baddley, J.W.; Patel, M.; Bhavnani, S.M.; Moser, S.A.; Andes, D.R. Association of fluconazole pharmacodynamics with mortality in patients with candidemia. Antimicrob. Agents Chemother. 2008, 52, 3022-3028. [CrossRef] [PubMed]

14. Seleem, D.; Pardi, V.; Murata, R.M. Review of flavonoids: A diverse group of natural compounds with anti-Candida albicans activity in vitro. Arch. Oral. Biol. 2017, 76, 76-83. [CrossRef]

15. Abdelrahmman, K.; El-Behairy, M.F.; Alsherbiny, M.A.; Mazeed, T.E. In vitro activity of dihydropyrazole derivatives against Candida species. Bull. Fac. Pharm. Cairo Univ. 2018, 56, 80-82. [CrossRef]

16. Lobo, C.I.V.; Lopes, A.C.U.d.A.; Klein, M.I. Compounds with distinct targets present diverse antimicrobial and antibiofilm efficacy against Candida albicans and Streptococcus mutans, and combinations of compounds potentiate their effect. J. Fungi 2021, 7, 340. [CrossRef] [PubMed]

17. Patel, M.; Srivastava, V.; Ahmad, A. Dodonaea viscosa var angustifolia derived 5,6,8-trihydroxy-7,4' dimethoxy flavone inhibits ergosterol synthesis and the production of hyphae and biofilm in Candida albicans. J. Ethnopharmacol. 2020, 259, 112965. [CrossRef]

18. Lin, M.Y.; Yuan, Z.L.; Hu, D.D.; Hu, G.H.; Zhang, R.L.; Zhong, H.; Yan, L.; Jiang, Y.Y.; Su, J.; Wang, Y. Effect of loureirin a against Candida albicans biofilms. Chin. J. Nat. Med. 2019, 17, 616-623. [CrossRef]

19. Pricopie, A.I.; Ionuț, I.; Marc, G.; Arseniu, A.M.; Vlase, L.; Grozav, A.; Găină, L.I.; Vodnar, D.C.; Pîrnău, A.; Tiperciuc, B.; et al. Design and synthesis of novel 1,3-thiazole and 2-hydrazinyl-1,3-thiazole derivatives as anti-Candida agents: in vitro antifungal screening, molecular docking study, and spectroscopic investigation of their binding interaction with bovine serum albumin. Molecules 2019, 24, 3435. [CrossRef]

20. Illicachi, L.A.; Montalvo-Acosta, J.J.; Insuasty, A.; Quiroga, J.; Abonia, R.; Sortino, M.; Zacchino, S.; Insuasty, B. Synthesis and $\mathrm{dft}$ calculations of novel vanillin-chalcones and their 3-aryl-5-(4-(2-(dimethylamino)-ethoxy)-3-methoxyphenyl)-4,5-dihydro-1hpyrazole-1-carbaldehyde derivatives as antifungal agents. Molecules 2017, 22, 1476. [CrossRef]

21. Andrade, J.T.; Santos, F.R.S.; Lima, W.G.; Sousa, C.D.F.; Oliveira, L.; Ribeiro, R.; Gomes, A.; Araújo, M.G.F.; Villar, J.; Ferreira, J.M.S. Design, synthesis, biological activity and structure-activity relationship studies of chalcone derivatives as potential anti-Candida agents. J. Antibiot. 2018, 71, 702-712. [CrossRef] [PubMed]

22. Seleem, D.; Benso, B.; Noguti, J.; Pardi, V.; Murata, R.M. In vitro and in vivo antifungal activity of lichochalcone-a against Candida albicans biofilms. PLoS ONE 2016, 11, e0157188. [CrossRef]

23. Pereira Fde, O.; Mendes, J.M.; Lima, I.O.; Mota, K.S.; Oliveira, W.A.; Lima Ede, O. Antifungal Activity of geraniol and citronellol, two monoterpenes alcohols, against Trichophyton rubrum involves inhibition of ergosterol biosynthesis. Pharm. Biol. 2015, 53, 228-234. [CrossRef]

24. Ma, H.; Zhao, X.; Yang, L.; Su, P.; Fu, P.; Peng, J.; Yang, N.; Guo, G. Antimicrobial peptide amp-17 affects Candida albicans by disrupting its cell wall and cell membrane integrity. Infect. Drug Resist. 2020, 13, 2509-2520. [CrossRef]

25. Douglas, L.M.; Konopka, J.B. Plasma membrane organization promotes virulence of the human fungal pathogen Candida albicans. J. Microbiol. 2016, 54, 178-191. [CrossRef]

26. Bahrin, L.G.; Sarbu, L.G.; Hopf, H.; Jones, P.G.; Babii, C.; Stefan, M.; Birsa, M.L. The influence of halogen substituents on the biological properties of sulfur-containing flavonoids. Bioorg. Med. Chem. 2016, 24, 3166-3173. [CrossRef]

27. Leite, M.C.A.; Bezerra, A.P.d.B.; Sousa, J.P.D.; Guerra, F.Q.S.; Lima, E.d.O. Evaluation of antifungal activity and mechanism of action of citral against Candida albicans. Evid.-Based Complement Altern. Med. 2014, 2014, 378280. [CrossRef]

28. Babii, C.; Mihalache, G.; Bahrin, L.G.; Neagu, A.N.; Gostin, I.; Mihai, C.T.; Sarbu, L.G.; Birsa, L.M.; Stefan, M. A novel synthetic flavonoid with potent antibacterial properties: In vitro activity and proposed mode of action. PLoS ONE 2018, 13, e0194898. [CrossRef]

29. Tempesti, T.C.; Alvarez, M.G.; de Araújo, M.F.; Catunda Júnior, F.E.A.; de Carvalho, M.G.; Durantini, E.N. Antifungal Activity of a novel quercetin derivative bearing a trifluoromethyl group on Candida albicans. Med. Chem. Res. 2012, 21, 2217-2222. [CrossRef]

30. Wang, S.; Wang, Q.; Yang, E.; Yan, L.; Li, T.; Zhuang, H. Antimicrobial compounds produced by vaginal Lactobacillus crispatus are able to strongly inhibit Candida albicans growth, hyphal formation and regulate virulence-related gene expressions. Front. Microbiol. 2017, 8, 564. [CrossRef] [PubMed]

31. Trevors, J.T.; Merrick, R.L.; Russell, I.; Stewart, G.G. A comparison of methods for assessing yeast viability. Biotechnol. Lett. 1983, 5, 131-134. [CrossRef]

32. Djordjevic, D.; Wiedmann, M.; McLandsborough, L.A. Microtiter plate assay for assessment of Listeria monocytogenes biofilm formation. Appl. Environ. Microbiol. 2002, 68, 2950-2958. [CrossRef] 